PURPose: To investigate whether caffeic acid phenethyl ester (CAPE) and cortisone prevent proliferative vitreoretinopathy (PVR).

Methods: Twenty pigmented rabbits were used in this study. All rabbits except controls received an intravitreal injection of $0.15 \mathrm{ml}(75,000 \mathrm{U})$ of platelet-rich plasma into their left eye. The animals were divided into four groups: group I was treated with intraperitoneal injection of $0.5 \mathrm{ml}(15 \mu \mathrm{mol} / \mathrm{kg})$ of CAPE for 3 days, group II received $0.15 \mathrm{ml}(4 \mathrm{mg} / \mathrm{kg})$ of intravitreal cortisone, group III received nothing (blank group), and group IV (control group) received only 1 ml of $1 \%$ ethanol intraperitoneally daily for 3 days. Proliferative changes were graded in a masked fashion by indirect ophthalmoscopy for a 15-day followup period. The malondialdehyde (MDA), reduced glutathione (GSH) and total nitrite (NO) levels were measured in the vitreous humor.

Results: The grades of PVR were $B-C$ in group $I$, and $C-D$ in group II. The PVR grade in the control group was $C-D$. The mean MDA level in group I $(4.0 \pm 0.8$ $\mu \mathrm{mol} / \mathrm{l})$ was significantly lower than in the blank group $(6.0 \mu \mathrm{mol} / 1)(p<0.05)$. The mean GSH level in group I $(71.0 \pm 11.2 \mu \mathrm{mol} / 1)$ was significantly different than in the blank group $(p<0.05)$. The MDA and GSH levels in group II were $4.7 \pm 0.6 \mu \mathrm{mol} / 1$ and $53.8 \pm 7.8 \mu \mathrm{mol} / 1$, respectively. Both these levels were not significantly different from the blank group $(p>0.05)$. The NO levels in both treatment groups were significantly lower than in the blank group $(p<0.001)$.

Conclusion: These findings suggest an inhibitory effect of CAPE on PVR. The inhibitory effect was supported by lower MDA and NO with higher GSH levels in treatment groups than in the blank group. There was no detected significant effect of cortisone for preventing PVR experimentally.

Key words: Caffeic acid phenethyl ester, Cortisone Proliferative vitreoretinopathy

\section{Use of caffeic acid phenethyl ester and cortisone may prevent proliferative vitreoretinopathy}

\author{
Yusuf Turkoz ${ }^{1}$, Hamdi Er ${ }^{2, C A}$, Mehmet Borazan², \\ Harun Yılmaz ${ }^{2}$, Bülent Mızrak ${ }^{3}$, Hakan Parlakpınar ${ }^{4}$ \\ and Yılmaz Çigremis ${ }^{5}$
}

${ }^{1}$ Department of Biochemistry, ${ }^{2}$ Department of Ophthalmology, ${ }^{3}$ Department of Pathology, ${ }^{4}$ Department of Pharmacology and ${ }^{5}$ Department of Biology, Inonu University Turgut Ozal Medical Center, Malatya 44069, Turkey

\author{
${ }^{\mathrm{CA}}$ Corresponding author: \\ Tel: +904223410660/4002 \\ Fax: +904223410619 \\ E-mail: hamdier@inonu.edu.tr
}

\section{Introduction}

Proliferative vitreoretinopathy (PVR) is a complex process involving inflammation, migration and proliferation of retinal pigment epithelial cells., ${ }^{1,2}$ Several inflammatory cytokines and growth factors are involved in these processes. PVR is the most common cause of failure in the treatment of retinal detachment and other vitreoretinal procedures. Previous studies have shown that different pharmacologic therapies may modify the proliferative process and improve the success of surgery. ${ }^{3,4}$ The migration of retina pigment epithelial cells is an important step in PVR. Therefore, blockage of the retina pigment epithelial cell migration might be useful in preventing proliferation.
Caffeic acid phenethyl ester (CAPE) is a potent antioxidant agent produced by the hives of honeybee propolis. It has antioxidant, antiproliferative, antiviral, antibacterial, cytotoxic anti-inflammatory, and immunomodulator properties. ${ }^{5-7}$ Most of these properties were attributed to two components of propolis, which are CAPE and flavonoids. CAPE has also been reported to inhibit the lipid peroxidation and the growth of different types of abnormal transferred cells. Therefore, we speculated that CAPE might prevent PVR by its antiproliferative and antioxidant effects.

Cortisone mainly suppresses intraocular inflammation in the body. Cortisone inhibits the expression of vascular growth factors and angionetic cytokines and contributes to the integrity of the blood-retina 
barrier. ${ }^{8}$ Our aim in this study was to investigate the possible antiproliferative effects of CAPE and cortisone in the pathophysiology of experimental PVR.

\section{Methods}

\section{Animals and experimental procedures}

Twenty pigmented rabbits of either sex, weighing at least $2 \mathrm{~kg}$, were used in this experiment. All animals were treated according to the ARVO Resolution on the Use of Animals in Research. The rabbits except controls were given intravitreal injections of $0.15 \mathrm{ml}$ (75,000 U) of platelet-rich plasma to the left eye. The animals were divided into four groups: group I was treated with intraperitoneal injection of $0.5 \mathrm{ml}$ ( $15 \mu \mathrm{mol} / \mathrm{kg}$ ) of CAPE for 3 days, group II received $0.15 \mathrm{ml}(4 \mathrm{mg} / \mathrm{ml})$ of intravitreal cortisone, group III received nothing (blank), and group IV (control group) received only $1 \mathrm{ml}$ of $1 \%$ ethanol intraperitoneally daily for 3 days. The eyes were examined by ophthalmoscopy to assess the proliferation during a 15-day follow-up period. Proliferative changes were graded in a masked fashion by indirect ophthalmoscopy. PVR was graded according to the classification of the Retina Society.

Animals were anesthetized with an intramuscular injection of ketamine hydrochloride $(\mathrm{HCl})(30 \mathrm{mg} / \mathrm{kg}$, intramuscularly) and xylazine hydrochloride $(5 \mathrm{mg} /$ $\mathrm{kg}$, intramuscularly). Topical application of $0.5 \%$ proparacaine hydrochloride was also used for local anesthesia. Precautions were taken at the time of each posterior chamber puncture to ensure that the vitreous humor was not contaminated by bleeding and to avoid contact with any structure of the posterior chamber. The samples of vitreous humor were collected and stored at $-40^{\circ} \mathrm{C}$ until used to measure the malondialdehyde (MDA), reduced glutathione (GSH) and total nitrite (NO) levels. The rabbits were then killed with an intravenous overdose of pentobarbital sodium for pathological examination.

\section{MDA and GSH analysis}

The MDA content was determined by the method of Ohkawa et al. ${ }^{10}$ That is, $0.2 \mathrm{ml}$ of $8.1 \%$ sodium dodecyl sulfate (SDS), $1.5 \mathrm{ml}$ of $3 \mathrm{M}$ acetate buffer and $1.5 \mathrm{ml}$ of $0.82 \%$ thiobarbituric acid were added in succession to $0.25 \mathrm{ml}$ of vitreous humor. The mixture was cooled to room temperature, $0.5 \mathrm{ml}$ of $35 \%$ SDS was added and the tubes were heated as already described for an additional $10 \mathrm{~min}$. The mixture was then cooled, centrifuged, and the optical density of supernatant was read at $532 \mathrm{~nm}$. The MDA concentrations in vitreous humor were expressed as micromoles per liter.
Reduced glutathione was estimated by Ellman's method. ${ }^{11}$ That is, $0.5 \mathrm{ml}$ of $10 \%$ trichloroacetic acid solution was added to $0.5 \mathrm{ml}$ of vitreous humor. A protein-free supernatant was obtained by centrifugation. Four milliliters of $0.3 \mathrm{M} \mathrm{Na}_{2} \mathrm{HPO}_{4}$ and $0.5 \mathrm{ml}$ of 5,5'-dithiobis (2-nitrobenzoic acid) were added to 0.5 $\mathrm{ml}$ of this supernatant. The intensity of the resulting yellow color was read spectrophotometrically at 410 nm. The GSH concentrations were calculated by comparing with the standard absorptions and were expressed as micromoles per liter.

\section{Total nitrite}

Nitrate was reduced to nitrite by incubating $0.25 \mathrm{ml}$ of the collected vitreous humor for $60 \mathrm{~min}$ with $50 \mathrm{mU}$ of nitrate reductase, $200 \mu \mathrm{mol} / 1$ reduced nicotinamide adenine dinucleotide phosphate and $10 \mu \mathrm{mol} / \mathrm{l}$ flavine adenine dinucleotide. NO was then measured by adding one volume of Griess reagent, prepared before use by mixing equal volumes of $2 \% p$ aminobenzene sulfonamide in 5\% phosphoric acid and $0.2 \% \quad N$-(I-naphthyl)ethylenediamine dihydrochloride. The absorbance was read at $540 \mathrm{~nm}$ against a sodium nitrate standard curve.

\section{Statistical analysis}

Statistical analysis was carried out using a nonparametric test (analysis of variance) for comparison of controls with experimental values at the different times. $p<0.05$ was considered statistically significant.

\section{Results}

The grades of PVR were $\mathrm{B}-\mathrm{C}$ and $\mathrm{C}-\mathrm{D}$ in group I and II, treated with with CAPE and cortisone, respectively. The PVR grade in the blank group was C-D (Fig. 1 and Table 1).

The mean MDA level in group I $(4.0 \pm 0.8 \mu \mathrm{mol} / \mathrm{l})$ was significantly lower than in the blank group (6.0 $\mu \mathrm{mol} / \mathrm{l})(p<0.05)$. The mean GSH level in group I $(71.0 \pm 11.2 \mu \mathrm{mol} / 1)$ was significantly higher than in the blank group $(48.5 \mu \mathrm{mol} / 1)(p<0.05$; Table 1$)$.

The MDA and GSH levels in group II, who received cortisone, were $4.7 \pm 0.6 \mu \mathrm{mol} / 1$ and $53.8 \pm 7.8 \mu \mathrm{mol} /$ 1 , respectively. Both these levels were not significantly different from the blank group $(p>0.05)$.

The mean vitreous concentration of NO in group I was $516 \pm 76.1 \mu \mathrm{mol} / 1$ and in group II was $501 \pm 60.8$ $\mu \mathrm{mol} / \mathrm{l}$. Both levels were significantly lower than in the blank group $(837 \pm 102.6 \mu \mathrm{mol} / 1) \quad(p<0.001)$ (Table 1). There was no significant difference in MDA, GSH, and NO levels between groups I and II $(p>0.05)$. 


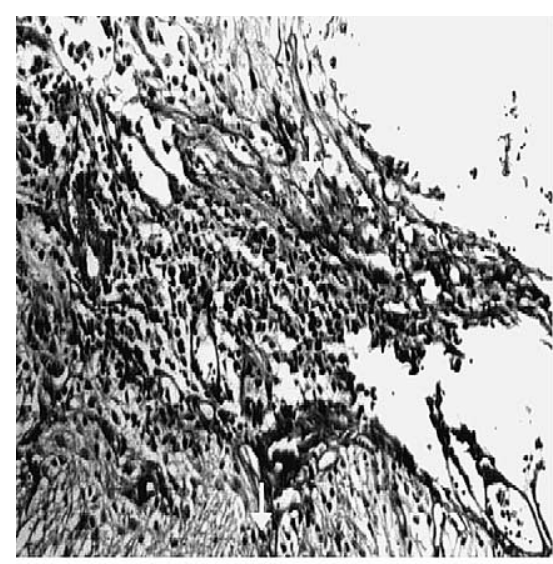

(a)

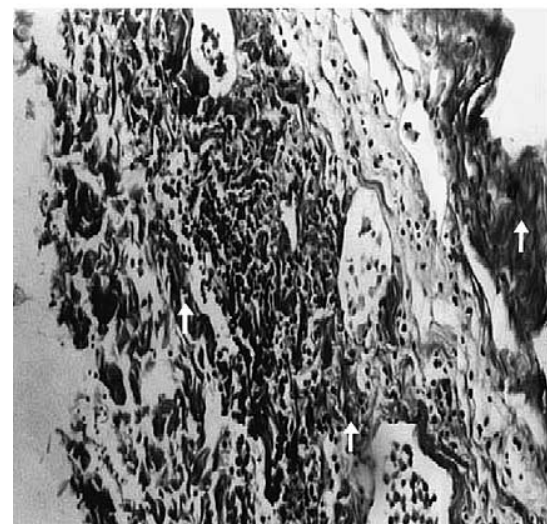

(c)

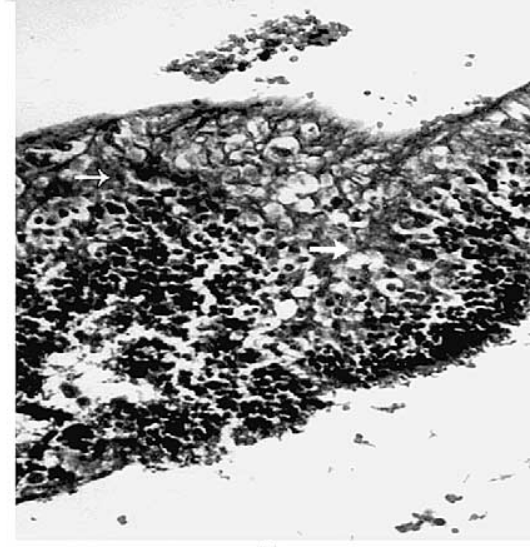

(b)

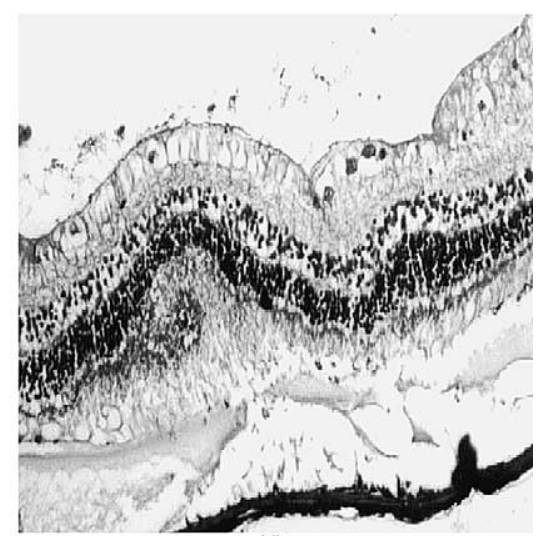

(d)

FIG. 1. (a) Normal retinal structure is generally preserved except a focus composed of connective tissue in group I. Arrows indicate collagen deposition (stain, Masson's trichrome; original magnification, $\times 50$ ). (b) Normal structure is extensively distorted with collagen deposition in group II eyes treated with cortisone. Arrows show collagen deposition (stain, Masson's trichrome; original magnification, $\times 50$ ). (c) The retina is replaced by connective tissue with large areas of collagen deposition in the blank group. Arrows exhibite collagen deposition (stain, Masson's trichrome; original magnification, $\times 50$ ). (d) Normal retina in the control group (stain, Masson's trichrome; original magnification, $\times 50$ ).

\section{Discussion}

Inflammation that increases the release of chemotactic and mitogenic factors stimulates the proliferation. Inflammation results in a decrease of GSH activity and an increase in MDA content, thus confirming the involvement of oxidative stress in the pathophsiology of the process. Reactive nitrogen species, mainly NO, play a role in inflammation. There is significant increase in nitric oxide synthase (NOS) activity of ocular tissues during the inflammatory process. NOS is induced in many types of cells, including macrophages, neutrophils and vascular smooth muscles, and is thought to be associated with some pathologic conditions involving these cell types. ${ }^{12}$ The inhibition of NOS decreases tissue damage and inflammation. NO levels in the vitreous humor of groups I and II were significantly lower than the blank group. We suggest that this reduced $\mathrm{NO}$ activity is due to suppression of the inducible forms of NOS by CAPE and cortisone. NO levels were positively correlated with disease chronicity as well as plasma MDA levels. Although NO is one of the well-known free radicals in the body associated with oxidative stress, its role in the etiopathogenesis of the PVR is still unclear.

CAPE and flavonoids are active components of honeybee propolis extracts. Propolis is a natural honey bee hive product. Both these compounds

Table 1. PVR grades and MDA, GSH and NO levels in vitreous humor

\begin{tabular}{lllll}
\hline Group & MDA $(\mu \mathrm{mol} / \mathrm{l})$ & \multicolumn{1}{c}{ GSH $(\mu \mathrm{mol} / \mathrm{l})$} & \multicolumn{1}{c}{ NO $(\mu \mathrm{mol} / \mathrm{l})$} & PVR grade \\
\hline CAPE* $^{*}$ & $4.0 \pm 0.8,<0.05$ & $71.0 \pm 11.2,<0.05$ & $516 \pm 76.1,<0.001$ & B-C \\
Cortisone $^{*}$ & $4.7 \pm 0.6,>0.05$ & $53.8 \pm 7.8,>0.05$ & $501 \pm 60.8,<0.001$ & C-D \\
Blank & $6.0 \pm 1.0$ & $48.5 \pm 11.3$ & $837 \pm 102.6$ & D \\
Control & $3.2 \pm 1.5$ & $95.7 \pm 51.7$ & $389 \pm 65.1$ & -
\end{tabular}

Data presented as mean \pm standard deviation, $p$ value.

* Statistical values between group I and the blank group by analysis of variance.

* Statistical values between group II and the blank group by analysis of variance. 
have been demonstrated to be anti-inflamatory, antiviral, antioxidative, antimitogenic and to have cytostatic activity. ${ }^{5-7}$ CAPE inhibits both lipooxygenase and cyclooxgenase pathways. Therefore, it might contribute to the anti-inflammatory activity of propolis. CAPE suppresses the proliferation and collagen synthesis properly by reducing the reactive oxygen intermediates; this is consistent with the antioxidant property of CAPE. ${ }^{13}$ CAPE may also exert its antiinflammatory effect by inhibiting the inducible NOS expression. ${ }^{14}$

Cortisone suppresses the activation and release of various inflammatory mediators, including polymorphonuclear leukocytes, T lymphocytes, macrophages and eosinophils. Macrophages produce different angiogenetic cytokines such as interleukins and tumor necrosis factor. Cortisone therefore has potent angiogenetic properties. Cortisone suppresses arachidonic acid metabolism and maintenance of the integrity of the cell membrane. It has also inhibits growth factors that are part of the major stimulating factors for development of PVR. ${ }^{8}$ The anti-inflammatory and immunosuppresive effects of corticosteroids are related to inhibition of NOS induction. Cortisone reduces the induction of NOS in many organs. ${ }^{15}$ This finding suggests that, in part, NO might be responsible for tissue damage of the anti-inflammatory and immunosuppressive actions of cortisone.

Various pharmacologic agents including 5-fluorouracil, heparin, daunorubicin and cortisone have been used against PVR. ${ }^{16,17}$ The present study investigated the therapeutic role of exogenous CAPE and cortisone in the pathophysiology of experimental PVR. Our results showed that CAPE was effective at least partly in the development of proliferation. This effect was associated with a significant reduction of NO and MDA levels, while increasing GSH levels. These results show that CAPE protects GSH from oxidation in addition to less lipid peroxidation with its potent antioxidant effect on the vitreous humor. No significant therapetic effect of the cortisone in the treatment of experimental PVR was detected.

In conclusion, we investigated the preventive effects of CAPE and cortisone in platelet-rich plasma-induced PVR formation in rabbit vitreous humor and found that CAPE is effective at least partly in the inhibition of PVR experimentally. The clinical results of both agents were correlated with NO, MDA and GSH levels. These findings may encourage the development of new studies designed to block the inflammatory and proliferative response more specifically and effectively.

\section{References}

1. Kon CH, Occleston NL, Aylward GW, Khaw PT. Expression of vitreous cytokines in proliferative vitreoretinopathy: a prospective study. Invest Ophthalmol Vis Sci 1999; 40: 705-712.

2. Von Horn DL, Aaberg TM, Machemer R. Glial cell proliferation in human retinal detachment with massive periretinal proliferation. Am J Ophthalmol 1977; 84: 383-393

3. Asaria RHY, Kon $\mathrm{CH}$, Bunce $\mathrm{C}$, et al . Adjuvant 5-fluorouracil and heparin prevents proliferative vitreoretinopathy. Ophthalmology 2001; 108: $1179-1183$

4. Daniels SA, Coonley KG, Yoshizumi MO. Taxol treatment experimental proliferative vitreoretinopathy. Graefes Arch Clin Exp Ophthalmol 1990; 228: $513-516$.

5. Focht J, Hansen SH, Nielsen JV, van den Berg-Segers A, Riezler R. Bactericidal effect of propolis in vitro against agents causing upper respiratory tract infections. Drug Res 1993; 43: 921-923.

6. Dobrowlski JW, Vohoro SB, Sharma K, Shah SA, Naqvi SAH, Dandiya PC. Antibacterial, antifungal, antiamoebeic, antiinflamatory, and antipyretic studies on propolis bee products. J Ethnopharmacol 1991; 35: 77-82.

7. Nagaoka T, Banskota AH, Tezuka Y, Saiki I, Kadota S. Selective antiproliferative activity of caffeic acid phenethyl ester analogues on highly liver-metastatic murine colon 26-L5 carcinoma cell line. Bioorg Med Chem 2002; 10: 3351-3359.

8. Er H, Gunduz A, Turkoz Y, Cigli A, Isci N. Effects of $\mathrm{N}^{\mathrm{G}}$-nitro L-arginine and corticosteroids on aqueous humor levels of nitric oxide and cytokines after cataract surgery. J Cataract Refract Surg 1999; 25 : $795-799$.

9. The Retina Society Terminology Committee. The classification of retinal detachment with proliferative vitreoretinopathy. Ophthalmology 1983; 90: $121-125$.

10. Ohkawa H, Ohishi N, Yagi K. Assay for lipid peroxides in animal tissues by thiobarbituric acid reaction. Anal Biochem 1979; 95: 351-358.

11. Ellman GL. Tissue sulfhydryl groups. Arch Biochem Biophys 1959; 82: $70-77$.

12. Mandai M, Mitttag TW, Kogishi J, et al. Role of nitric oxide synthase isozymes in endotoxin-induced uveitis. Invest Ophthalmol Vis Sci 1996; 37: $826-832$

13. Zhao WX, Zhao J, Liang CL, Zhao B, Pang RQ, Pan XH. Effect of caffeic acid phenethyl ester on proliferation and apoptosis of hepatic stellate cells in vitro. World J Gastroenterol 2003; 9: 1278-1281.

14. Song YS, Park EH, Hur GM, et al. Caffeic acid phenethyl ester inhibits nitric oxide synthase gene expression and enzyme activity. Cancer Lett 2002; 175: 53-61.

15. Nauck M, Roth M, Tamm M, Eickelberg O, Wieland H, Stulz P, Perruchoud AP. Induction of vascular endothelial growth factor by platelet-activating factor and platelet-derived growth factor is downregulated by corticosteroids. Am J Respir Cell Mol Biol 1997; 16: $398-$ 406.

16. Hegazy HM, Peyman GA, Liang C, Unal MH, Molinari LC, Kazi AA. Use of perfluorocarbon liquids, silicone oil, and 5-fluorouracil in the management of experimental PVR. Int Ophthalmol 1998-99; 22: $239-246$.

17. Hui YN, Hu D. Prevention of experimental proliferative vitreoretinopathy with daunomycin and triamcinolone based on the time course of the disease. Graefes Arch Clin Exp Ophthalmol 1999; 237: 601-605.

\section{Received 16 December 2003 \\ Accepted 23 January 2004}




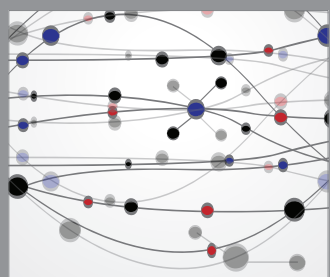

The Scientific World Journal
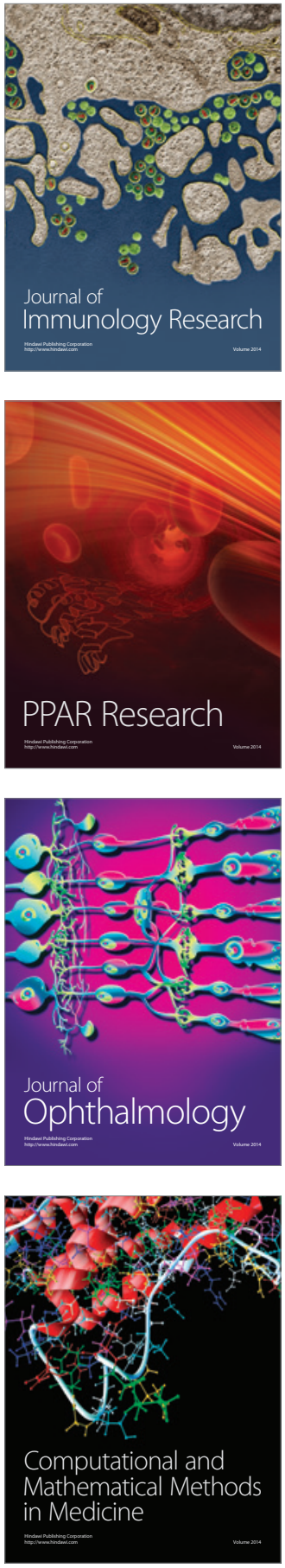

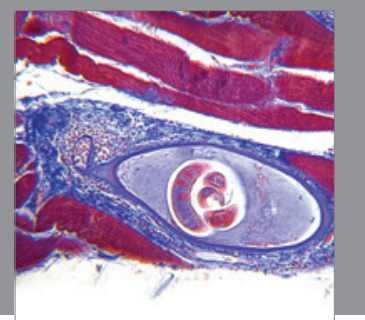

Gastroenterology

Research and Practice
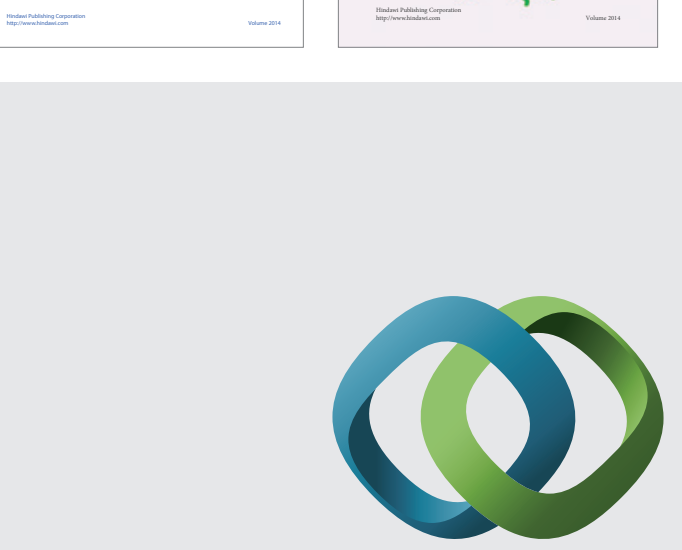

\section{Hindawi}

Submit your manuscripts at

http://www.hindawi.com
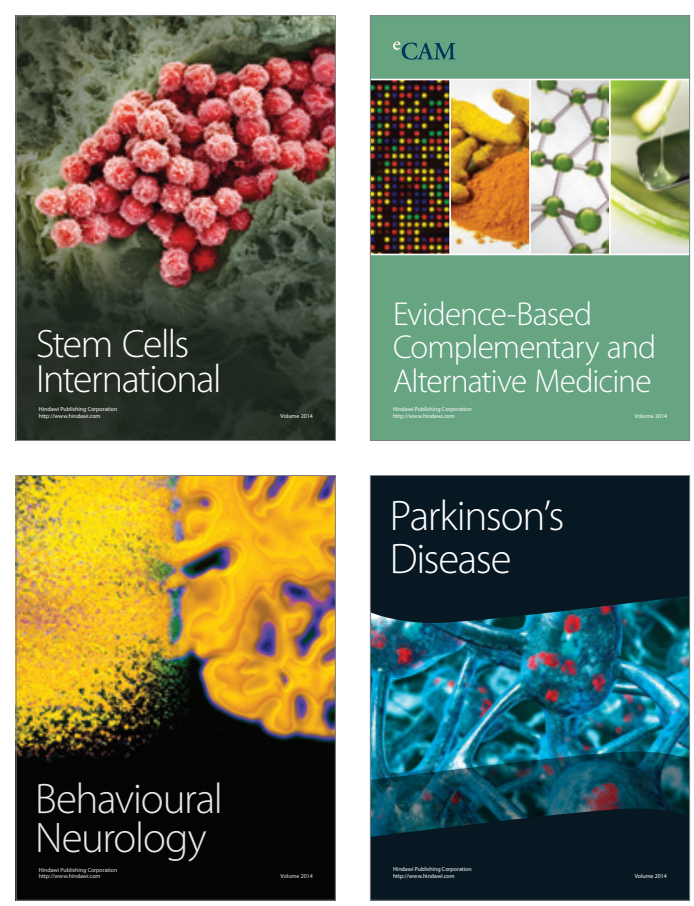

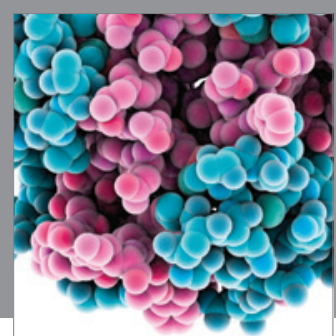

Journal of
Diabetes Research

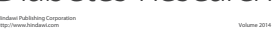

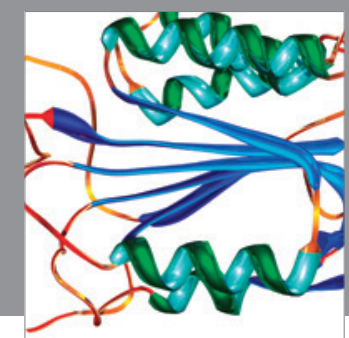

Disease Markers
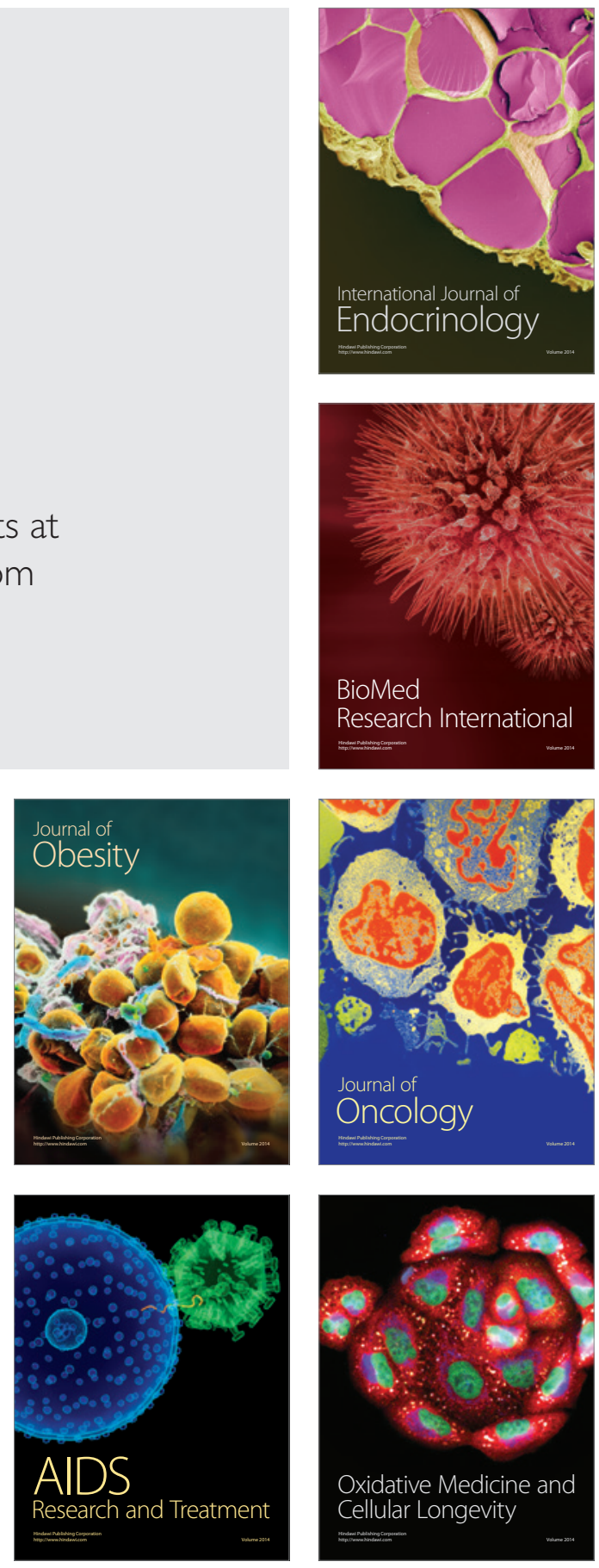